ISSN: 0213-2052 - eISSN: 2530-4100

DOI: https://doi.org/10.14201/shha202139107134

\title{
LA GEOGRAFÍA DEL LACUS LIGUSTINUS EN ESTRABÓN 3.1.9
}

\section{The Geography of the lacus Ligustinus in Strabo 3.1.9}

Pepa CASTILLO PASCUAL

Universidad de La Rioja

mariajose.castillo@unirioja.es

ORCID: https://orcid.org/0000-0003-0002-3336

Pilar IGUÁCEL DE LA CRUZ

Universidad de La Rioja

pilar.iguacel@unirioja.es

ORCID: https://orcid.org/0000-0002-9145-095X

Fecha de recepción: 16-11-2020 Fecha de aceptación: 6-05-2021

RESUMEN: Este artículo analiza un parágrafo de la Geografía de Estrabón que recoge el derrotero desde Gadeira hasta el Promontorio Sagrado (3.1.9). Gracias a la información que proporciona este texto, combinada con la de los estudios arqueológicos, ofrecemos algunas puntualizaciones sobre el lacus Ligustinus entre la conquista romana y el cambio de era, que no habían sido contempladas hasta ahora, y que permiten reconstruir la trayectoria de la navegación en este entorno.

Palabras clave: Lacus Ligustinus; Asta; puerto de Menesteo; torre de Cepión; Baetis.

ABSTRACT: The aim of this paper is to analyse a paragraph of Strabo's Geography about the course from Gadeira to the Sacred Promontory 
(3.1.9). The information offered by this text, combined with archaeological and geo-archaeological studies, provides some details about the lacus Ligustinus' geography between the Roman conquest and the change of Era, which had not been taken into account so far. As a result, we are able to reconstruct the navigation route in this environment. Baetis.

Keywords: Lacus Ligustinus; Asta; port of Menestheus; tower of Caepio;

Estrabón fue un gran viajero, él mismo se vanagloria de ser el geógrafo que más territorios ha recorrido, desde Armenia hasta el Tirreno y desde el Mar Negro hasta las fronteras de Etiopía ${ }^{1}$. Sin embargo, nunca estuvo en el extremo occidente de la ecúmene, al que dedica el tercer libro de su Geografía. Por supuesto, no duda en justificar tal desconocimiento, que se debe a la imposible tarea de poder conocer de forma directa Oriente y Occidente al mismo tiempo, así como los países meridionales y septentrionales ${ }^{2}$. En cualquier caso, no le da demasiada importancia a este hecho, ya que considera que son suficientes los testimonios orales de aquellos que viajaron por estas tierras ${ }^{3}$, a los que habría que sumar los datos que obtuvo de geógrafos e historiadores anteriores, principalmente Polibio, Asclepíades de Mirlea, Artemidoro de Éfeso y Posidonio ${ }^{4}$.

Gracias a toda esta información Estrabón escribe su libro dedicado a la península ibérica, el punto de partida de su viaje a lo largo del mundo mediterráneo. En su relato la descripción del litoral costero siempre precede a la del interior peninsular y le sirve, junto con los ríos y la orografía, para ordenar el discurso. En lo referente a la descripción costera de Iberia, esta se articula a partir de dos promontorios: el Promontorio Sagrado y las Columnas de Hércules. Entre estos dos promontorios sitúa el litoral de lo que para Estrabón es el civilizado y floreciente sur, la Turdetania o Bética5. Comenzando por su línea costera, el geógrafo de Amasia elabora un relato de su paisaje geográfico e histórico que es casi un panegírico, no solo de la región per se, sino de las excelencias que la romanización y la Pax Romana de Augusto trajeron a la misma. Solo a partir de entonces floreció la proverbial riqueza económica de esta región de la ecúmene, atravesada por

1. Str. 2.5.11. Su predecesor Posidonio tan solo visitó Iberia y Galia.

2. $I b$.

3. Ib.

4. Sus principales fuentes fueron Artemidoro y Posidonio, que en torno al año $100 \mathrm{a}$ C. el primero y 95 a. C. el segundo estuvieron en la península ibérica. Sobre su influencia en Estrabón, Alonso-Núñez, "Les informations»; «Les renseignements».

5. Str. 3.1.2. 
excelentes vías de comunicación, sobre todo fluviales, y poblada con un elevado número de ciudades ${ }^{6}$. Estas fueron las ventajas de su integración en el circuito cultural y comercial del mare Nostrum, es decir, de Roma.

En este contexto de un hombre de letras griego que defiende la misión civilizadora de Roma, incluso cuando escribe sobre regiones que nunca ha visitado, es nuestro propósito analizar un parágrafo del primer capítulo del libro dedicado a Iberia. Son varias las razones que nos han llevado a ello, pero la principal es que se trata de un texto que refleja el paisaje geográfico y cultural del lacus Ligustinus en torno al siglo I a. C. y, a pesar de ello, la información que proporciona, o no se ha tenido en cuenta, o se ha interpretado erróneamente en la reconstrucción que se ha hecho de este entorno a partir de la documentación arqueológica y geoarqueológica. En definitiva, nuestra intención es combinar los datos arqueológicos y geoarqueológicos con una lectura crítica de algunos pasajes de la geografía de Iberia de Estrabón, para proponer una reconstrucción del lacus Ligustinus o, mejor dicho, de la trayectoria de la navegación en el ámbito de la desembocadura del Guadalquivir en torno al cambio de era.

\section{De Gadeira al Hieron Akroterion: Estrabón 3.1.97}

Una vez descritas las ciudades costeras desde el estrecho de Gibraltar hasta Gadeira (Cádiz), que para Estrabón es una de las ciudades más importantes de Occidente ${ }^{8}$, sigue la descripción de la costa hasta el Promontorio

6. Str. 3.2.3. Su visión es la de un imperio romano unitario y, por encima de todo, "romano-céntrica», en la línea de las Res gestae divi Augusti (Roddaz, "Aux marges", 102). Este milagro de Roma que admira Estrabón está claramente plasmado en 6.4.2 y 17.3.24-25.

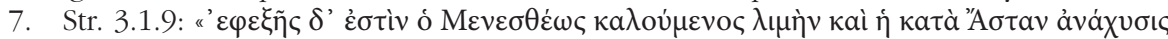

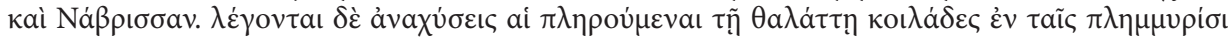

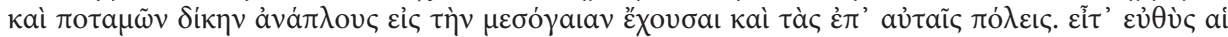

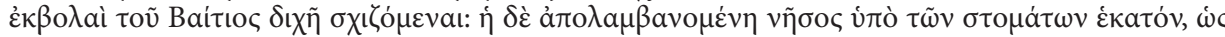

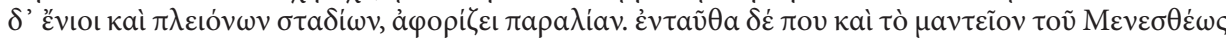

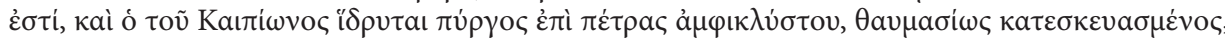

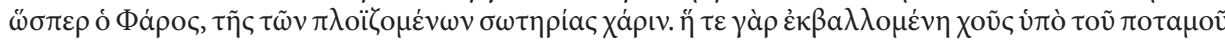

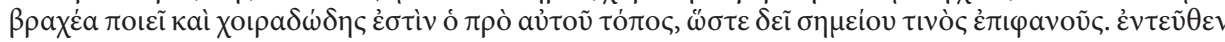

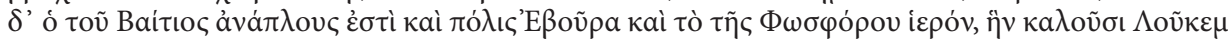

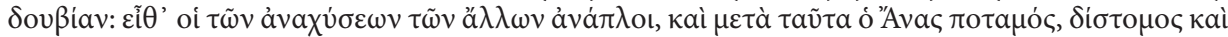

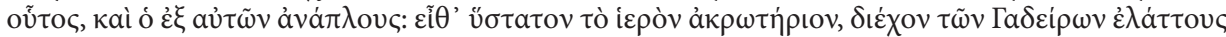

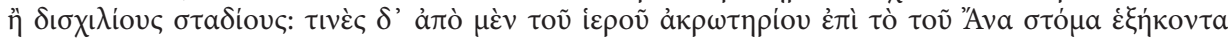

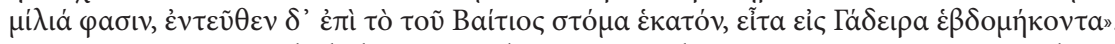

8. En número de habitantes solo es superada por Roma y en número de individuos del grupo ecuestre es asimilable a Patavium (Padua) (3.5.3). Evidentemente es una exageración, pero de esta manera el geógrafo remarca el dinamismo comercial de este enclave. 
Sagrado, que se corresponde, en parte, con el contexto geográfico y cultural del lacus Ligustinus y la desembocadura del Guadalquivir.

Comienza Estrabón mencionando que a continuación de Gadeira se

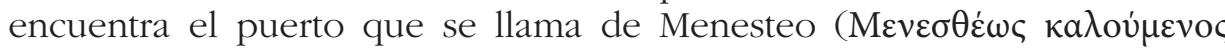
$\lambda \iota \mu \eta ́ v)$ y el estero (áváxvoıৎ) a la altura de Asta (Mesas de Asta) y Nabrissa (Lebrija). Tras señalar las ventajas que los esteros ofrecen a la navegación interior, sigue con su descripción de la línea costera, y su siguiente punto

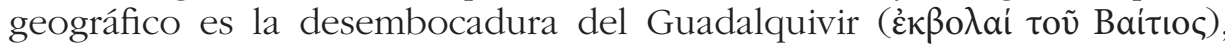
a la que se refiere en plural por estar dividida en dos caños que rodean una isla de cien estadios de costa $(18,5 \mathrm{~km})^{9}$, o más, según otros. Aquí

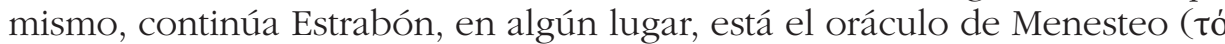

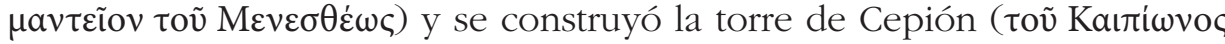
$\pi \dot{\rho} \rho \gamma o \varsigma)$ sobre unas rocas rodeadas por el mar, una obra admirable, como el Faro de Alejandría, que garantizaba la seguridad de los navegantes en una zona que, explica el geógrafo, es peligrosa debido a que los depósitos aluviales del río forman aguas poco profundas y el lugar frente al faro está lleno de rocas. A partir de aquí comienza el canal de mar que permite

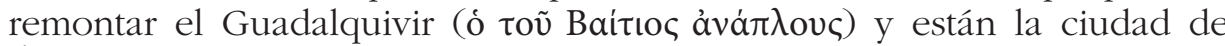

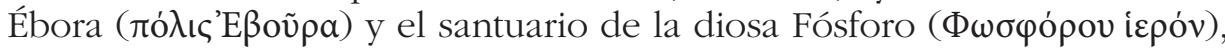

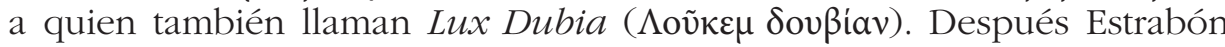
menciona los otros estuarios por los que se puede navegar río arriba, y a continuación de estos el Guadiana, que también tiene dos desembocaduras, y la navegación desde estas hacia el interior. Finalmente, llega al Promontorio Sagrado, que está a menos de dos mil estadios de distancia de Gadeira $(370 \mathrm{~km})$, y para otros a 240 millas $(340 \mathrm{~km})^{10}$.

Este esquema descriptivo es una herencia del género periplográfico griego, y aunque la obra de Estrabón, "historiador del espacio»"11, está muy alejada de este género, su nombre aparece en el catálogo que sobre los representantes de la periplografía escribió Marciano de Heraclea ${ }^{12}$.

9. A partir de 7.7.4 se ha aceptado mayoritariamente que el estadio de Estrabón equivale a 1/8 de milla, es decir, a 185 m (Geus y Guckelsberger, "Measurement data", 170). Sin embargo, estamos ante una medida marítima y fluvial que oscila entre 150 y $298 \mathrm{~m}$, a veces también en Estrabón (Arnaud, "Les routes", 85).

10. Esta cifra total está desglosada en el texto de la siguiente manera: 60 millas entre el Promontorio Sagrado y la desembocadura del Guadiana (88,8 km); 100 millas desde allí hasta la del Guadalquivir $(148 \mathrm{~km})$; y, por último, setenta millas desde ahí hasta Gadeira $(103,6 \mathrm{~km})$.

11. Cruz Andreotti, «La visión», 59.

12. Según Marciano, los periplos alcanzaron su cénit por su exhaustividad y precisión con Artemidoro de Éfeso, Estrabón y Menipo de Pérgamo (Epit. Menipp. 1.3, GGM I, p. 566, 4-8). Para un corpus periplográfico griego, González Ponce, Periplógrafos, 45-48; Olshausen, «Der Periplus», 44-57. 
Por otra parte, el propio Estrabón evidencia las carencias de los autores de periplos y portulanos en el ámbito de la geografía científica ${ }^{13}$. Sin embargo, es evidente que en su Geografía ha tenido a su disposición periplos para documentarse ${ }^{14}$, incluso afirma que al proceder así, usando "el mar como guía", emula a Éforo ${ }^{15}$. En el caso que nos ocupa, el geógrafo de Amasia elige un esquema de periplo como hilo conductor de un discurso que es histórico, en el que enumera los enclaves costeros siguiendo la línea del litoral turdetano, utilizando expresiones habituales en este género, que le sirven casi siempre para establecer una relación

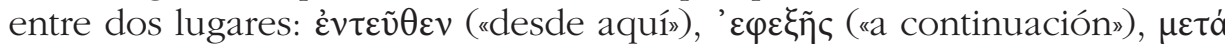

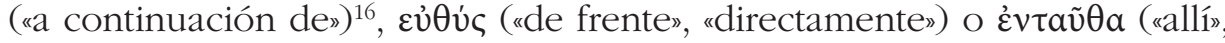
"allí mismo»). Además, proporciona las distancias en estadios y no olvida mencionar los riesgos que para la navegación tenían determinados puntos del recorrido a causa de bajíos, formaciones rocosas, mareas, etc.; indica también puertos, puntos desde los que se podía navegar hacia el interior a través de esteros o ríos, lugares de culto cerca de la costa, etc. ${ }^{17}$. Con todo, la información que facilita en comparación con la de un periplo es, según algunos, parca, sumaria y esquemática y, en consecuencia, poco útil para un navegante ${ }^{18}$. Tal afirmación no se puede hacer extensiva a otras costas, para las que disponía de mayor información y de un conocimiento directo, y en cuya descripción adopta incluso la perspectiva del navegante con frases como "cuando se navega fuera del golfo...", "cuando se navega hacia...", "cuando se navega hacia el sol naciente...", por citar algunos ejemplos ${ }^{19}$. Por lo tanto, su parquedad en los datos no se debe a que haya seleccionado la información periplográfica recopilada para las costas de Iberia, sino a la escasez de la misma, unido al hecho de que no visitó la península, lo que explicaría también la ausencia de la mencionada perspectiva del navegante.

En cualquier caso, aunque menosprecie el género periplográfico, es evidente que dispuso de periplos o narraciones en forma de periplo para

13. Str. 1.1.21. A Piteas de Marsella (s. IV a. C.), por ejemplo, le considera un embustero, y de la misma opinión es Polibio (2.4.1).

14. Str. 8.3.20.

15. Str. 8.1.3. En relación con este rasgo del periplo, Clarke, «Strabo», 48-49.

16. Esta preposición era muy habitual para alinear los enclaves costeros (Güngerich, Die Küstenbeschreibung, 11).

17. Sobre los elementos que formaban parte de estos periplos, Prontera, «Períploi», 37; González Ponce, «El corpus», 69; Olshausen, «Der Periplus», 41.

18. Prontera, «Períploi», 38/ 41-43; González Ponce, "El corpus», 69.

19. Str. 7.4.2; 7.4.5; 12.3.2; Str. 14.3.1. En el libro octavo está muy claro que la posición del observador es un barco $(8.3 .4 ; 8.3 .27 ; 8.5 .1,8.5 .2)$. 
informarse sobre la línea costera de una región que desconocía por completo, de hecho, dos de sus principales fuentes, Artemidoro y Posidonio, escribieron también periplos. Esta concepción hodológica del espacio estuvo presente desde los primeros geógrafos jonios hasta Plinio el Viejo, todos ellos nos proporcionan una descripción secuencial del litoral a lo largo de un determinado recorrido, y por eso pueden ser considerados, en mayor o menor medida, autores de periplos ${ }^{20}$. Por otra parte, los relatos en clave de periplo pueden ser interpretados como una expresión de hegemonía, de aspiración a un dominio universal ${ }^{21}$, de manera que esta forma de ordenar el relato era muy apropiada para un geógrafo de formación helenística que vivió bajo la Pax romana de Augusto.

\section{El DERROTERO haCia El OCÉANO: LOS PUNTOS DE REFERENCIA ${ }^{22}$}

En este derrotero Estrabón proporciona los puntos de referencia geográficos que eran visibles a los marineros en una travesía entre los actuales Cádiz y cabo de San Vicente, y lo hace siguiendo, claro está, el orden en el que aparecen durante la travesía, porque, como él mismo afirma, $\grave{\eta}$

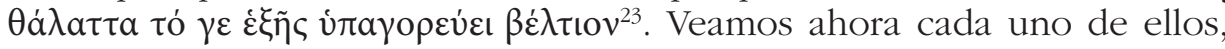
para los que, siempre que sea posible, propondremos una ubicación.

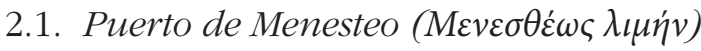

El primer enclave que Estrabón menciona tras Gadeira es el puerto de Menesteo, un topónimo que responde a la creencia estraboniana de una colonización mítica, la de los nóstoi, los héroes griegos que tras terminar la guerra de Troya padecieron un largo viaje de regreso a su hogar. Nuestro geógrafo desvía hacia el lejano Occidente a varios de ellos, no solo a Menesteo, sino también a Odiseo, Anfíloco, Antenor, Ocela, Teucro, Menelao y Diomedes, a los que presenta como piratas que llegan aquí atraídos por las riquezas ${ }^{24}$. Ninguno de ellos procede de las grandes regiones de la colonización arcaica (Focea, Jonia, Eubea), pero sí de ciudades

20. Arnaud, "Les routes", 66.

21. Ejemplos de esta función hegemónica los encontramos entre los asirios y los persas, y quizá los relatos periplográficos de fenicios y griegos deberían interpretarse de la misma manera (Kaplan, "The function", 39-42).

22. Para facilitar la lectura del texto adjuntamos dos mapas (Figs. 1 y 2) y una tabla con las distancias mencionadas en el texto (Fig. 3), vid. infra.

23. Str. 9.2.21.

24. Str. 3.2.13. 
y regiones de la Grecia posterior, principalmente del Ática y en concreto Atenas; así mismo, los espacios a los que aparecen vinculados, que no son míticos sino históricos, no se corresponden con importantes enclaves del proceso colonial en esta zona ${ }^{25}$.

Veamos el caso de Menesteo, que ha dado nombre a un puerto y a un oráculo. Nuestro protagonista pertenecía a la familia real de Antenas por ser hijo de Peteo ${ }^{26}$, y aparece en el catálogo de las naves de la Ilíada como jefe del contingente ateniense en la guerra de Troya ${ }^{27}$. Es decir, tenemos a un ateniense en el entorno de la bahía de Cádiz, cuyo culto, como sostiene Salinas de Frías, pudo ser introducido tras la segunda guerra púnica (218-201 a. C.) a instancias de comerciantes de origen ático ${ }^{28}$. Durante la segunda centuria asistimos a un renacimiento comercial de Atenas, no solo porque la ciudad se había volcado hacia el nuevo poder que había surgido en el Mediterráneo, Roma, sino también porque la decadencia de Rodas dejaba un vacío comercial que no tardó en ocupar la patria de Menesteo $^{29}$. A todo esto hay que sumar el filohelenismo de los gobernadores romanos que, vinculados muchos de ellos al círculo de los Escipiones, apoyarían y fomentarían el establecimiento de gentes procedentes de Grecia $^{30}$.

Sin embargo, la presencia de Menesteo en estos parajes pudo ser anterior. Filóstrato de Atenas hace referencia a una estrecha relación entre Gadeira y los atenienses; al alto grado de helenización de la ciudad fenicia, evidente en su aprecio por los atenienses; que rindiesen culto a uno de sus reyes legendarios, Menesteo, o que hubiesen erigido una estatua de bronce en honor de Temístocles, por su sabiduría y valor ${ }^{31}$. Por otra parte, desde la segunda mitad del siglo V y a lo largo de todo el IV a. C. es muy abundante la cerámica ática en el sur peninsular, precisamente cuando los focenses ya habían perdido su control comercial sobre el Mediterráneo occidental, ahora en manos de etruscos y cartagineses, y Gadeira establecía nuevos pactos comerciales con los segundos para mantener su

25. En relación con esta cuestión, Salinas de Frías, «Los elementos", 208-210.

26. Hom. Il. 4.327; 4.338; Apollod. 3.10.8; Plut. Thes. 32.1. En otras tradiciones Peteo es su padre putativo y él es hijo del río Esperqueo (Apollod. 3.13.4), fue colocado en el trono por los Dióscuros cuando estos liberaron a Helena, raptada por Teseo, de la que también fue pretendiente Menesteo (Apollod. 3.10.8).

27. Hom. Il. 2.546-556.

28. Salinas de Frías, "El Hierón Akroteríon", 144-145.

29. Salinas de Frías, "Los elementos», 213.

30. $I b$.

31. Philostr. Vit. Apol. 5.4 . 
posición en el tráfico del Estrecho ${ }^{32}$. En este contexto de los siglos V y IV a. C., una actividad comercial en el entorno de la bahía de Cádiz llevada a cabo por atenienses podría explicar perfectamente tanto el puerto como el oráculo de Menesteo ${ }^{33}$.

Para completar lo anterior, es de gran interés la interpretación de Antonelli sobre la presencia de Menesteo en Occidente ${ }^{34}$. A finales del siglo V a. C. cobra fuerza la tradición que recoge un cierto antagonismo político entre Teseo, artífice del sinecismo ático y, en consecuencia, representante de la ideología democrática, y Menesteo, defensor de la independencia de los reinos áticos ${ }^{35}$; se recoge incluso el viaje de Menesteo a Iberia como un exilio, al margen de la tradición de los nóstoi. A partir de esta tradición, Antonelli concluye que la presencia de este rey ateniense en Iberia podría estar relacionada con intentos propagandísticos de algunas facciones políticas, sin descartar que pudo ser también una invención ateniense para legitimar sus ambiciones hegemónicas en el lejano Occidente ${ }^{36}$. Por otra parte, este ámbito geográfico, por su carga simbólica, se convertía en el paraje perfecto donde los círculos aristocráticos proyectaban su utópico deseo de retornar a la constitución de sus antepasados, es decir, a la Atenas de Menesteo ${ }^{37}$.

Al margen de estas interpretaciones, el objetivo de Estrabón al situar a los nóstoi en el sur de Iberia es convertir este espacio liminal en un espacio más del ámbito cultural del Mediterráneo, que es griego y romano. También le sirve para mostrar que en la base del grado de civilización alcanzado por los turdetanos, los más sabios de los îberos ${ }^{38}$, están los contactos que han mantenido con los griegos.

Con respecto a su ubicación debemos tener en cuenta que es muy probable que enclaves fenicios y púnicos fuesen asimilados por la elite romana filohelena a esta toponimia mítica griega ${ }^{39}$, seguramente para

32. Montero Vítores, «El yacimiento», 42.

33. Una breve visión del contexto comercial de este ámbito geográfico entre los siglos VIII-III a. C. en Montero Vítores, «El yacimiento», 37-41.

34. Antonelli, 1997, 161-163.

35. Esta oposición es recogida por Plutarco (Thes. 32.1).

36. Antonelli, I Greci, 168. En este sentido, Fabré sostiene que el conjunto de leyendas sobre su migración sirve para justificar la política ateniense de expansión comercial y de lucha antisiracusana que se manifiesta en la segunda mitad s. V a. C. (Fabré, Les grecs, 138).

37. $I b$.

38. Estrabón aclara que hacen uso del alfabeto, han escrito su historia y tienen poemas y leyes (3.1.6).

39. Plácido Suárez, «Conocimiento», 163-164. 
ennoblecer los orígenes de tales lugares ${ }^{40}$. Este sería el caso también del puerto de Menesteo, que Estrabón sitúa entre Gadeira y el estero junto a Asta y Nabrissa, por lo tanto, en la desembocadura-estuario del Guadalete ${ }^{41}$. En este entorno, el sitio arqueológico Castillo de Doña Blanca (Puerto de Santa María) se presenta como el lugar más adecuado para localizar aquí el puerto de Menesteo. Se trata de una ciudad fortificada cuya zona arqueológica es de casi 400 ha, y en ella se incluyen, entre otros vestigios, un puerto en su entrada sudeste y una posible zona portuaria a $250 \mathrm{~m}$ al sur de la ciudad ${ }^{42}$. Su privilegiada situación geoestratégica, a los pies de la sierra de San Cristóbal y a orillas del estuario del Guadalete, explican su dilatada existencia desde su fundación en torno a 800 a. C. hasta los siglos III-IV d. C., destacando su notable desarrollo urbano desde finales del siglo VI a. C. y durante el siglo V a. C., momento en el que establece relaciones comerciales con ciudades griegas, que se intensificarán en el siglo IV a. C. ${ }^{43}$. Esta cronología del Castillo de Doña Blanca encaja perfectamente con la actividad comercial de gentes procedentes de Atenas a la que nos hemos referido anteriormente.

A partir de las coordenadas proporcionadas por Ptolomeo, Montero Vítores localiza este puerto en el área arqueológica de la Dehesa de Bolaños, en el fondo del antiguo estuario del Guadalete y al este del Castillo de Doña Blanca ${ }^{44}$. Sin embargo, el hecho de que la zona no se haya excavado todavía y que solo tengamos la información proporcionada por sondeos de prospección no permite afirmar que el campamento romano que Ponsich quiso ver en la fotografía aérea de 1956 corresponda, en realidad, a estructuras portuarias debajo de las que «hay sin duda un asentamiento anterior que responde al momento fundacional de Puerto de Menesteo, en el Gadir fenicio", tal como afirma Montero Vítores ${ }^{45}$. En esta propuesta las coordenadas de Ptolomeo se han convertido en el único argumento posible para ubicar este puerto, sin tener en cuenta lo arriesgado de manejar

40. En relación con esta forma de proceder, Gómez Espelosín, Pérez Largacha y Vallejo Girvés, La imagen, 101-102.

41. La idea generalmente admitida de la vinculación del puerto de Menesteo con Gadeira lleva a pensar a Montero Vítores que debió estar unido a esta ciudad, de la misma manera que el del Pireo lo estaba con Atenas o el de Ostia con Roma (Montero Vítores, «El yacimiento", 55). Bochardt sugería la idea de relacionarlo con Asta (Bochardt 1646, apud Montero Vítores, «El yacimiento", 55). Por otra parte, no creemos que se deba identificar con el puerto que Balbo construyó a los gaditanos, que Estrabón sitúa en Gadeira y en ningún momento lo identifica con el de Menesteo (Str. 3.5.3).

42. Una síntesis de la historia de este enclave en Ruiz Mata, "Gadir», 266-273.

43. Ruiz Mata, "Gadir", 271-272.

44. Ptol. 2.4. 5. Montero Vítores, «El yacimiento», 54-55.

45. Montero Vítores, «El yacimiento», 54. 
las cifras proporcionadas por nuestras fuentes, sean estas de distancias o de coordenadas.

Aunque entraña cierto riesgo acudir al papiro de Artemidoro (PArtemidoro), que en su columna $\mathrm{V}$ recoge el derrotero que analizamos aquí y las distancias entre los puntos geográficos del mismo ${ }^{46}$, no podemos dejarlo a un lado, tanto por la coincidencia en el recorrido como por la communis opinio de que Estrabón toma de Artemidoro todo lo referido a medidas, dimensiones y topónimos ${ }^{47}$. Asimismo, somos conscientes de la dificultad de establecer una equivalencia precisa de las medidas y de que la estimación de las distancias variaba considerablemente de un autor a otro. El estadio, que es la unidad de medida que nos interesa aquí, es una unidad de medida que, como ya hemos mencionado, oscila entre 150-298 m y un mismo autor podía utilizar valores diferentes ${ }^{48}$.

En este documento, el viaje a lo largo de la costa occidental comienza en la torre y puerto de Menesteo, que está a 86 estadios (entre 12,9-25,6 $\mathrm{km}$ ) de Gadeira, una distancia que sitúa el puerto de Menesteo en el continente. Marciano ${ }^{49}$, que siempre proporciona una distancia mínima y otra

46. PArtemidoro V, 11. 28-36.

47. Gómez Espelosín et al., La imagen, 54. Si bien en 1998 este papiro fue atribuido a Artemidoro por la coincidencia entre la columna IV del papiro y el frag. 21 de la obra del geógrafo griego en Stihle 1856, 203 (fragmento conservado en Hdn. Pros. Cath. 3.1, p. 288.28 Lentz; St. Byz. 324.4; Const. Porph. Admin. Imp. 23.13), las discusiones sobre si era auténtico o una falsificación comenzaron tras su exposición en Turín, en febrero de 2006. A la cabeza de los que defienden su autenticidad están, entre otros, Gallazzi, Kramer y Settis, editores de la editio princeps (Gallazzi, Kramer y Settis, Il Papiro) y en la posición contraria el principal representante es Canfora, quien desde 2006 ha publicado numerosos artículos en este sentido; destacamos una monografía que apareció en 2008, antes que la editio princeps, Canfora, Il papiro. Con todo, tal y como afirma Moret, las columnas IV y V se pueden atribuir «con cierto grado de confianza a la Geografía de Artemidoro, o si no fuera él directamente, a un abreviador activo entre el siglo I a. C. e inicios del I d. C.» a partir de evidencias paleográficas y de una datación radiocarbónica del papiro (Moret, "Artemidoro", 429). Para un estado de la cuestión, Marcotte, "Le papyrus"; Condello, "Artemidoro"; Pajón Leyra, "Vicisitudes»; Bossina, "Il cosiddetto». Sobre la relación entre el frag. 21 y el PArtemidoro, que marca el inicio de la polémica, Hammerstaedt, "Artemidorus».

48. Sobre esta cuestión, Arnaud, Les routes, 84-87. En el caso de Artemidoro, Moret ha demostrado que, para el trayecto Pirineo-Gades, el geógrafo griego se basaba en un itinerario terrestre, de manera que las distancias que proporciona son producto de convertir las millas en estadios, sobre la base de un factor 1:8 (Moret, "Artemidoro", 447-451), es decir, 1 estadio $=185 \mathrm{~m}$. Sin embargo, no hay evidencia alguna de que esto sea así para el itinerario que aquí analizamos, de manera que nos moveremos en la horquilla de equivalencia en metros entre la que oscila el estadio (150-298 m), convertidos en kilómetros.

49. Recogemos también la información de Marciano de Heraclea porque este, además de hacer un resumen de la obra de Artemidoro (Geographoumena), la utilizó como fuente documental para la suya (Periplus maris exteri). Sentía por el geógrafo griego una 
máxima, solo menciona el puerto, no la torre, y lo sitúa a 225 (máx.) o 160 estadios (mín.) desde el promontorio junto al Estrecho; añade que por estos lugares está la isla de Gadeira, en el mar exterior, hasta la que hay desde el mismo promontorio 270 (máx.) o 240 (mín.) estadios ${ }^{50}$. Sus cifras no nos aclaran mucho, pero es evidente que tampoco sitúa el puerto de Menesteo en Gadeira, sino a una distancia que oscila entre 45 (6,7-13,41 $\mathrm{km})$ y 80 estadios $(12-23,8 \mathrm{~km})$ y en la península.

Las distancias de Artemidoro y Marciano tan solo nos muestran que el puerto de Menesteo se encontraba cerca de Gadeira y en el continente, pero nada más ${ }^{51}$. La torre ( $\left.\pi \dot{\rho} \rho \gamma o \varsigma\right)$ que menciona el primero en relación con el puerto, y que no es recogida ni por Estrabón ni por ningún otro autor, sería la tradicional baliza portuaria para señalar la bocana del puerto ${ }^{52}$.

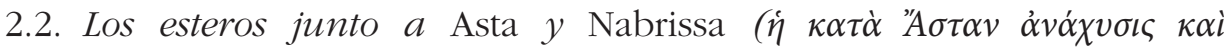 Nóß $\beta \iota \sigma \sigma \alpha v)$}

Para Estrabón los esteros, al igual que los ríos, tienen una gran importancia, porque posibilitan el comercio y abren las puertas a la explotación económica del interior. El geógrafo los define como depresiones o barran-

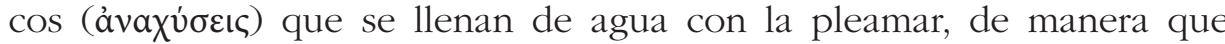
pueden desempeñar el mismo papel que los ríos navegables ${ }^{53}$. Tal circuns-

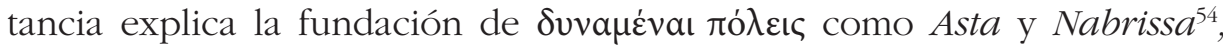
que llegaron a serlo porque seguramente el estero junto al que estaban situadas no se quedaría sin agua durante la bajamar, algo que no ocurría siempre pues, como refiere el propio Estrabón, algunos de estos esteros sí

gran admiración por su rigor y exactitud en los datos (Marcian. Epit. Menipp. 1.3, GGM I, p. 566.4-8; 1.4, GGM I, p. 567.1-2; 1.3, GGM I, p. 566.29-41; Peripl. 2.1, GGM I, p. 542, 15 26), aunque esto no le impide añadir o corregir sus textos, e incluso actualizar el viaje por la costa (Marcian. Peripl. pr., GGM I, p. 516.1-13; Epit. Menipp. 1.4, GGM I, p. 567.23-33).

50. Marcian. Peripl. 2.9, GGM I, p. 545, 15-23.

51. En el mapa del SIGPAC, la distancia en línea recta entre la actual Cádiz y el yacimiento del Castillo de Doña Blanca es de $c a .16 \mathrm{~km}$, lo que estaría en consonancia con las medidas dadas por ambos.

52. Ejemplos de estas torres portuarias habría en los puertos fenicios de $A k k o$ (Acre), Sidón y Atlit (Peña Olivas, «Señalización», 8-9).

53. Str. 3.1.9. Para definir este tipo de navegación utiliza el término ảvám $\lambda$ ovৎ, cuyo significado concreto es el de "navegación por un canal del mar en el interior de un país", además del genérico de «navegación remontando el curso del agua desde su desembocaduraw.

54. Str. 3.2.5. 
que se vaciaban ${ }^{55}$. Pero no era fácil, refiere el geógrafo de Amasia, navegar por ellos debido a que la fuerza de la pleamar empujaba con fuerza en sentido contrario a la corriente de estos cursos de agua, tanto en el descenso hacia el mar como cuando se navegaba hacia el interior; a esto hay que añadir la posibilidad de que la embarcación se quedase varada ${ }^{56}$. Con todo, era muy ventajoso para el desarrollo económico de la región situada entre el Promontorio Sagrado y las Columnas de Hércules, la zona de los esteros que hoy en día es el paisaje marismeño del Guadiana y del Guadalquivir.

La situación geoestratégica de Asta y Nabrissa en este entorno era claramente privilegiada no solo por estar a la orilla de un estero que funcionaba como si de un río se tratase, sino porque tanto una como otra estaban ubicadas sobre acrópolis naturales, la primera en el cabezo de Mesas de Asta y la segunda en el cerro del Castillo ${ }^{57}$, de manera que ambas han tenido un hábitat continuado, Asta desde el Neolítico hasta la Alta Edad Media y Nabrissa desde el Calcolítico hasta hoy.

Sin embargo, en palabras de Estrabón, la ciudad "más conocida" de los esteros es Asta, que está situada a "no mucho más de cien estadios más allá del puerto de la isla” y donde los gaditanos se reúnen habitualmente en asamblea ${ }^{58}$. El reducido tamaño de la isla de Gades supuso el asentamiento de gran parte de la población en las tierras continentales del arco costero de la bahía de Cádiz, donde se han localizado villas rústicas, figlinae y fondeaderos ${ }^{59}$. Esto explicaría, en el marco de este paisaje histórico de la bahía de Cádiz, que la excelente situación geoestratégica de Asta, en el reborde del lacus Ligustinus y rodeada de esteros navegables, convirtiese a este enclave en un mejor punto de encuentro que la propia Gades. Su ubicación justificaría también que Julio César le otorgase el estatuto colonial ${ }^{60}$, en lo que también influiría que durante la guerra civil con Pompeyo equites Romani Astenses se pasaron al bando cesariano ${ }^{61}$.

55. Str. 3.2.4.

56. Ib.

57. La designación de "cabezo» en el caso de Mesas de Asta hace referencia a los acantilados del estuario.

58. Str. 3.2.2. Una evidencia de la importancia y poder de Asta en su entorno es el Bronce de la Torre Lascutana (190 o 189 a. C.) en el que se recoge el decreto del pretor Lucio Emilio Paulo que liberaba a una población, los habitantes de Torre Lascutana, sometida a los de Asta.

59. En relación con las figlinae, Lagóstena Barrios y Bernal Casasola, "Alfares», 85.

60. Mela 3.4; Plin. NH 3.11. Como colonia de César en González Fernández, Colonia Hasta, 224; aunque Ferreiro López considera que no hay indicios suficientes para hablar de una promoción cesariana (Ferreiro López, Asta Regia, 169).

61. Bell. Hisp. 26.1-2. Sobre esta cuestión, Martín-Arroyo Sánchez, Colonización romana, 154-155. 
Por el contrario, Nabrissa no corrió la misma suerte, recibió el sobrenombre de Veneria, pero no fue promocionada ni a colonia ni a municipio, al menos hasta los Flavios ${ }^{62}$.

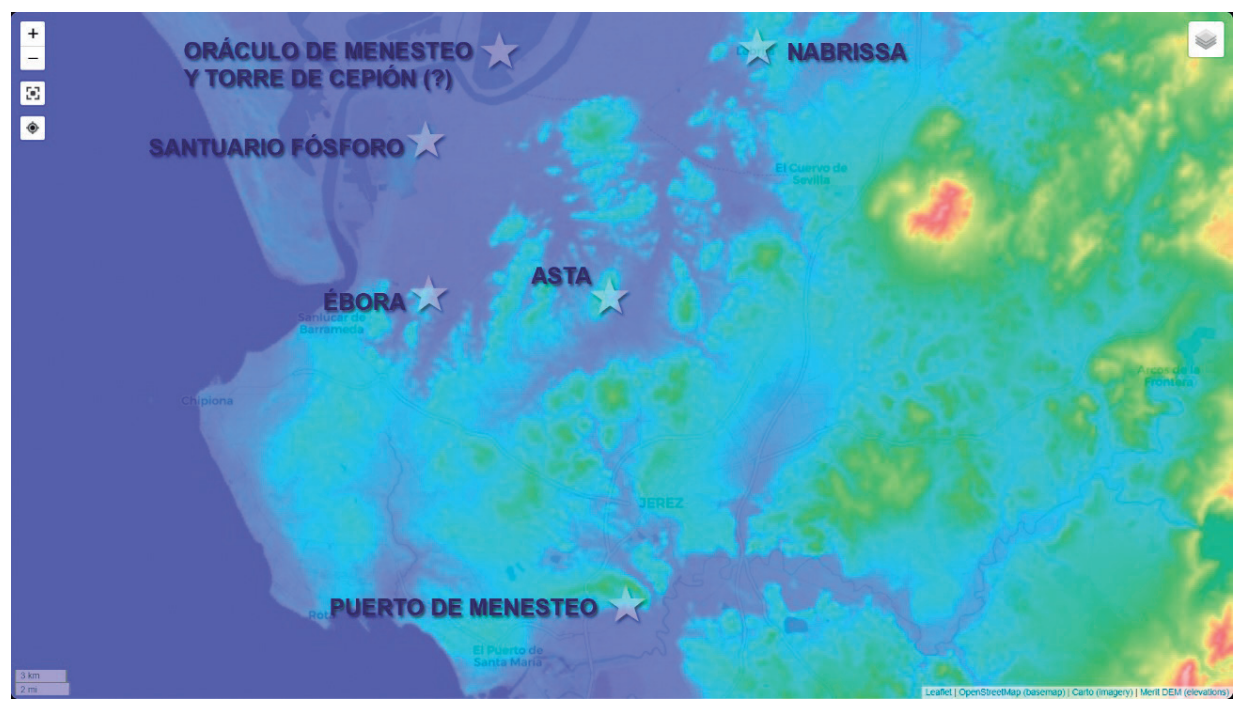

Fig. 1. Mapa de los esteros con la ubicación de los puntos de referencia. Elaborado a partir de https://es-es.topographic-map.com/maps/6olb/España/

La ubicación de Asta y Nabrissa no ofrece duda alguna y, en consecuencia, tampoco la de los esteros que las bañaban, pero nos plantea una ruta de navegación que no ha sido tenida en cuenta hasta ahora. El texto de Estrabón es un relato periplográfico, de manera que evidencia una ruta navegable directa desde el puerto de Menesteo hasta aquí, es decir, desde algún punto de la ribera derecha del estuario del Guadalete hasta el lacus Ligustinus. Este trayecto solo sería posible a través de los esteros y canales que, en algunos casos, fueron excavados pensando en el comercio interior y exterior, tal y como afirma Estrabón ${ }^{63}$. En esta dirección apuntaría también la distancia de 120 estadios $(18-35,7$ km) del PArtemidoro para el trayecto desde el puerto y la torre de Menesteo hasta «la

62. Plin. NH 3.11. Caro Bellido, "Nabrissa», 66. Para hallazgos de época romana en el casco urbano de Lebrija, Caro Bellido, Lebrija. Sobre la evolución de este enclave al ritmo de la formación del paisaje marismeño, Tomassetti, "Contribución".

63. Str. 3.2.5. Sobre este sistema estuariano de las desembocaduras del Guadalete y Guadalquivir, "de los quales algunos aun oi se demuestra» escribe Antonio de Nebrija en su Muestra de las Antigüedades de España (Nebrija, Muestra, cap. Iiif). 
desembocadura del $A_{s t a}{ }^{64}$, que sería la boca del estero junto a $A s t a^{65}$. En el caso de Estrabón, aunque para este trayecto el punto de partida parece que no es el puerto de Menesteo, sino el de Gadeira, por ser el enclave geográfico más importante de la zona, la distancia de «no mucho más de 100 estadios" $(18,5 \mathrm{~km})$ apunta también en este sentido ${ }^{66}$. Es evidente, por lo tanto, que en este derrotero no se circunnavega la costa entre la actuales Rota y Sanlúcar de Barrameda, evitándose así los vientos y corrientes desfavorables, además de los bajíos y barras presentes a lo largo de todo este tramo, como la "barra de Sanlúcar», a la que parece referirse Estrabón cuando menciona que los aluviones arrastrados por el río forman bajíos en una zona de escollos ${ }^{67}$.

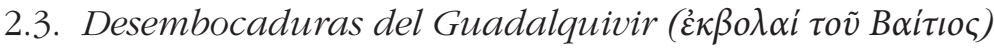

El siguiente punto de esta travesía son las desembocaduras del Guadalquivir, de las que, si bien nada dice sobre la distancia a la que estaban,

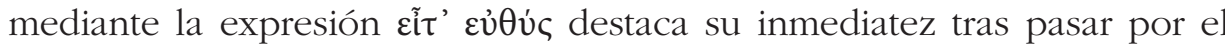

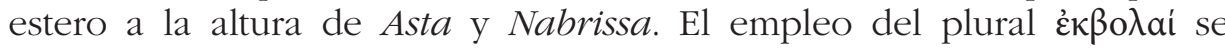
explica porque es una desembocadura dividida en dos $\operatorname{caños}^{68}$, entre los que se había formado una isla con un perímetro de cien estadios $(18,5$ $\mathrm{km})$, medida que para algunos, añade Estrabón, sería mayor. No especifica aquí ni quiénes lo afirman así ni el número de estadios que proponen, pero este desacuerdo no sería fruto de errores de cálculo, sino del

64. En Moret los 120 estadios equivaldrían a 15 millas, sin mencionar el itinerario terrestre en el que se habría basado Artemidoro (Moret, "Artemidoro», 448-450).

65. No es ni un hidrónimo ni una ciudad denominada Asta en la costa atlántica, entre el puerto de Menesteo y las desembocaduras del Guadalquivir, como afirman Gallazzi, Kramer y Settis, quienes, al no tener en cuenta las características geográficas de este entorno ni una posible ruta directa a través de los esteros, tal y como planteamos aquí, proponen la existencia un enclave homónimo a Hasta Regia en la costa para explicar el trayecto "desembocadura del Asta - río Baetis» del PArtemidoro (Gallazzi, Kramer y Settis, Il Papiro, 245-246).

66. Str. 3.2.2. Es posible que Estrabón se refiera aquí a una realidad portuaria mucho más extensa, dependiente de Gadeira, que abarcaría el arco de la bahía de Cádiz y el estuario del Guadalete, en la que el puerto de Menesteo era un enclave más. En este sentido, Celestino Pérez y López Ruiz sugieren que el Castillo de Doña Blanca, en cuyas inmediaciones creemos que estaría el puerto de Menesteo, podría haber sido una extensión del primitivo asentamiento fenicio en Cádiz, con la finalidad de proporcionar un puerto adicional en el continente y facilitar así las comunicaciones con el interior (Celestino Pérez y López Ruiz, Tartessos, 141).

67. Str. 3.1.9.

68. En 3.2.11 también hace referencia a estas dos desembocaduras. 
hecho de tratarse de un caso de insula in flumine nata o islote de lodo mareal sometido a una continua variación estacional de su contorno en función de la pleamar o la bajamar.

En tiempos del emperador Claudio, el geógrafo hispanorromano Pomponio Mela también señala esta doble desembocadura. Afirma que el Guadalquivir fluye desde su nacimiento por un solo cauce, pero a poca distancia del mar forma un lago del que sale bifurcado en dos brazos, siendo el caudal de cada brazo similar al del río antes de su división ${ }^{69}$. Plinio, por el contrario, menciona los esteros del Baetis donde ubica Nabrissa y Asta, pero nada dice de esta doble desembocadura en su Historia Natural, cuyos primeros libros se publicaron en torno al año $77 \mathrm{~d}$. C. ${ }^{70}$. De desembocaduras en relación con este río hablan también Plutarco en su vida de Sertorio y Ptolomeo ${ }^{71}$; en el siglo II d. C. Pausanias menciona las dos bocas de este río ${ }^{72}$, y dos siglos más tarde lo hace Avieno en su Ora maritima, quien llama al Guadalquivir río Tarteso y hace una descripción de un paisaje que es el característico de un río anastomosado, tema sobre el que volveremos más adelante ${ }^{73}$.

Este punto geográfico no aparece en el periplo de PArtemidoro, en el que se menciona el río Baetis a continuación de la «desembocadura del Asta", a una distancia de 84 estadios $(12,6-25 \mathrm{~km})^{74}$. Marciano, por su parte, menciona la desembocadura más oriental del Baetis y proporciona una distancia máxima de 385 estadios $(57,75-114,73)$ y una mínima de 285 $(42,7-84,9)^{75}$. En ambos casos, el siguiente punto geográfico de su recorrido es Onoba (Huelva), sin mencionar ninguno de los otros enclaves que recoge Estrabón, y que, como veremos, se deberían situar antes de salir al océano ${ }^{76}$. Es evidente que el primero concentra su atención en lo que ha considerado los enclaves más importantes para su periplo, y que Marciano le ha seguido, siendo sus distancias más acertadas. Con todo, ninguna refleja la «inmediatez» a la que alude Estrabón entre el estero a la altura de Asta y la doble desembocadura, porque, evidentemente,

69. Mela 3.5.

70. Plin. NH 3.11 .

71. Plut. Sert. 8; Ptol. Geog. 2.4.4.

72. Pausanias 6.19.3.

73. Av. O. m. 284-290.

74. PArtemidoro, col. V 28-30 (Gallazzi, Kramer y Settis, Il Papiro, 186-189).

75. Marcian. Peripl. 2.9, GGM I, p. 545, 26-27; 546, 1. Marciano sigue aquí a Ptolomeo, una de sus principales fuentes, quien tan solo alude a la «boca oriental del Betis» sin mencionar ni ubicar otra desembocadura (2.4.3).

76. Para un estudio del derrotero del PArtemidoro desde Onoba al Promontorio Sagrado y los problemas de localización de alguno de los puntos geográficos mencionados, Ruiz Acebedo y Campos Carrasco, «El litoral», 101-106. 


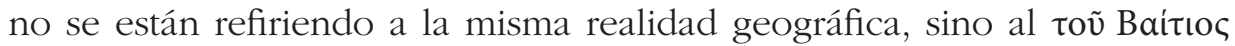

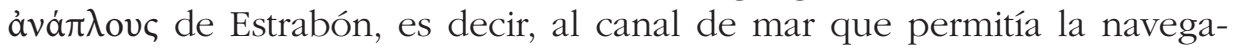
ción hacia el interior remontando el Guadalquivir y que era la salida del lacus Ligustinus al Océano.

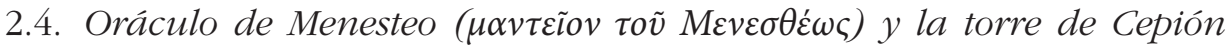 (}

En algún lugar de este paisaje de río poco definido, dividido en una red de canales divagantes separados por islotes de lodo, propios de estos escenarios y muchas veces estacionales, sitúa Estrabón el oráculo de Menesteo y la torre de Cepión, sin dar detalle alguno de su ubicación,

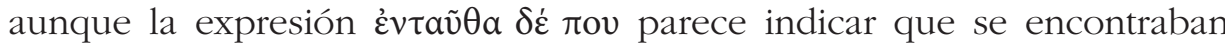
en el islote que dividía la desembocadura del Guadalquivir en dos caños. Este islote, sobre el que volveremos más adelante, se correspondería con el delta que se formó a la altura de Coria del Río y que en torno al cambio de era habría ido avanzando hacia el sur, hasta las cercanías del estero de Nabrissa.

En relación con el oráculo de Menesteo se ha apuntado la idea de que podría tratarse de un oráculo helenizado en el marco del Gadir púnico, al que se acudiría para hacer consultas sobre viajes marítimos y pedir protección durante los mismos; y esta helenización debería asociarse a la importancia de la ciudad tiria en las exportaciones de salazones hacia Atenas ${ }^{77}$. Montero Vítores, por su parte, propone que si bien el Gadir fenicio promovió el culto a Melkart para proteger las aventuras coloniales marítimas, el Gadir abierto a los contactos comerciales con Atenas impulsó el oráculo del héroe ateniense ${ }^{78}$.

La torre de Cepión es en el relato de Estrabón una estructura construida de manera admirable para la seguridad de los navegantes, al igual que la torre en la isla de Faro, el famoso Faro de Alejandría ${ }^{79}$. Esta comparación le lleva también a describir la ubicación de la torre en términos muy similares a los del Faro: sobre una estructura rocosa bañada toda

77. Blázquez Martínez, Diccionario, 175.

78. Montero Vítores, «El yacimiento", 55. Es de sobra conocido por todos el importante papel que los oráculos desempeñaron en la aventura colonial y comercial griega, de manera que no vamos a insistir en ello, remitimos para ello a Domínguez Monedero, "Los oráculos».

79. César también utiliza un término similar para referirse al Faro de Alejandría, mirificus opus (Caes. Civ. 3.112.1). 
alrededor por las olas ${ }^{80}$. Es muy posible que Estrabón, al no tener más información sobre la torre de Cepión que la de su nombre y su existencia en el entorno de la desembocadura del Guadalquivir, se limite a reproducir para esta la misma descripción que hace del Faro de Alejandría, y así la torre deja de ser una torre para convertirse en un faro. Parece que en esta ocasión no cuenta con la valiosa información de sus fuentes principales, Artemidoro y Posidonio, bien porque estos no conocían su existencia, o bien porque realmente no era un faro, lo que no significa que en determinadas circunstancias fuese utilizada como tal. Un indicio más en este sentido es el testimonio de Mela, quien no habla de pharus o turris phari sino de monumentum Caepionis, colocado scopulo magis quam insulae ${ }^{81}$.

Nuestra propuesta es que la torre no fue concebida en origen como un faro, sino como un monumento conmemorativo, mandado construir por Q. Servilio Cepión, cónsul en el año 140 a. C., tras su victoria sobre los lusitanos, tal y como se acepta mayoritariamente. En este mismo año Cepión llegó a la Ulterior para hacerse cargo de la dirección de la guerra contra Viriato, reemplazando a su hermano, Quinto Fabio Máximo Serviliano, que había firmado un acuerdo con Viriato que declaraba a este amigo del pueblo romano y confirmaba a los lusitanos la propiedad de las tierras que ocupaban ${ }^{82}$. La paz no duró mucho y Cepión, que consideraba que el tratado era injusto para Roma, lo rompió e inició las hostilidades ${ }^{83}$, que culminaron con el asesinato de Viriato y la derrota de los lusitanos ${ }^{84}$. Sin embargo, al cónsul vencedor de los lusitanos y de Viriato se le negó el triunfo en Roma, quizá por matar a Viriato con malas artes o conceder tierras a los vencidos ${ }^{85}$. Con seguridad, ambas actuaciones se convirtieron en excelentes argumentos en manos de sus oponentes políticos. En este contexto, Cepión ordenaría la construcción de un monumento turriforme que conmemorase y recordase sus victorias en Hispania, en el lejano Occidente. Un proceder muy propio de un miembro de la aristocracia romana filohelena ${ }^{86}$, que, al igual que Alejandro Magno y antes que él los persas,

80. La torre de Cepión está sobre unas rocas (Str. 3.1.9) y el Faro de Alejandría sobre

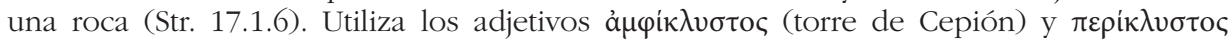
(Faro de Alejandría) con el mismo sentido, «bañado todo alrededor».

81. Mela 3.4. La imagen de Mela se acerca más a la del Faro de Alejandría (vid. supra)

82. App. $I b .69$.

83. App. $I b .70$.

84. App. Ib. 74-75.

85. Sobre el complot a Viriato, App. Ib. 74; Liv. Per. 44; Vell. 2.1.3; Val. Max. 9.6.4.

86. Plácido Suárez, "Conocimiento», 157. 
reivindicaba así el poder y la gloria sobre los territorios recién conquistados, en otras palabras, lo que el Senado de Roma le había negado ${ }^{87}$.

Poco más se puede saber sobre la torre de Cepión, incluso su ubicación es problemática ante la ausencia de vestigios arqueológicos. Nuestra propuesta parte del texto de Estrabón, de una nueva interpretación de este punto de referencia y, por supuesto, de la evolución geomorfológica del lacus Ligustinus, a la que nos referiremos más adelante y a modo de conclusión. A partir de estos supuestos, no creemos que se deba ubicar este monumentum en algún punto del tramo costero entre Sanlúcar de Barrameda y Chipiona, como la Piedra Salmedina, la ubicación más ampliamente aceptada y que partió de la descripción de Estrabón, una descripción que, como ya hemos señalado antes, es la del Faro de Alejandría ${ }^{88}$.

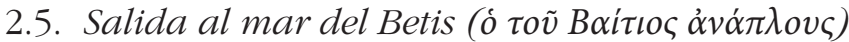

Llegamos después al canal de mar que permitía la navegación hacia el interior remontando el curso del Guadalquivir, es decir, la salida al mar del Guadalquivir. En este paraje Estrabón sitúa, además, la ciudad de Ébora y el santuario de la diosa Fósforo.

Si bien geomorfológicamente se ha probado la existencia de dos desembocaduras en torno al siglo I a. C. y el cambio de era, una entre la flecha litoral de Doñana y la isla de La Algaida y una secundaria entre dicha isla y las colinas de Sanlúcar de Barrameda ${ }^{89}$, Estrabón tan solo se refiere a este "canal", que podría ser la desembocadura más occidental, más ancha, profunda y estable que la orienta $1^{90}$. Prueba de ello es que la oriental se cerró a consecuencia de la progresiva progradación costera que afectó a esta zona entre los siglos I a. C. y II d. C., quedando la isla de La Algaida

87. En relación con la realeza persa, Kaplan, "The function", 40-42; sobre esta arquitectura de ostentación en Alejandro Magno, Olaguer-Feliú y Alonso, "Alejandro Magno», $11-18$.

88. Otras ubicaciones propuestas son el Santuario de Nuestra Señora de Regla, Punta del Perro o Piedra de Siete Brazas. Para una visión global de estas localizaciones, Gómez Muñoz, Turres Caepionis, 361-363.

89. Rodríguez Ramírez et al., "Geomorphological record", 115.

90. En estos términos es descrita por Rodríguez Ramírez et al., "Geomorphological record", 115 . 
unida mediante un tómbolo al continente al norte de Sanlúcar de Barrameda ${ }^{91}$ y la ciudad de Ébora sin una salida directa al mar ${ }^{92}$.

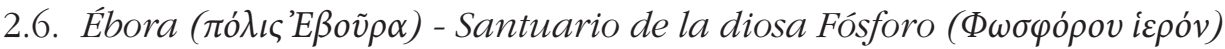

La ciudad de Ébora ha sido localizada en el actual Cortijo de Évora (Sanlúcar de Barrameda), lugar donde en 1958 fue descubierto el tesoro de origen orientalizante que lleva su nombre ${ }^{93}$. La importancia de este descubrimiento y la abundancia de material cerámico, principalmente turdetano y romano ${ }^{94}$, son indicio de la importancia del enclave, que se debe explicar por su excelente posición geoestratégica a orillas del lacus Ligustinus, tal y como dice Estrabón, en el acceso hacia el interior de la Turdetania remontando el Guadalquivir, de manera que no se puede descartar la función portuaria señalada por Menanteau ${ }^{95}$. Con todo, autores como Mela o Plinio apenas proporcionan información, el primero califica a este enclave de castellum y lo sitúa en la costa, el segundo lo denomina Cerialis ${ }^{96}$.

En el mismo entorno menciona el geógrafo de Amasia el santuario a la diosa Fósforo, que se ha identificado con el yacimiento de El Tesorillo, situado en el pinar de La Algaida, dentro del Parque Natural de Doñana, un santuario que estuvo en uso entre los siglos VI y II a. C. ${ }^{97}$.

Estamos ante un santuario costero de tradición marinera que bien pudo ejercer la función de faro o «hito costero» para señalar ó toṽ Baítıo àvá $\lambda \lambda o v \varsigma^{98}$. Un indicio en este sentido bien podría ser el nombre de la

91. Sobre este proceso de progradación costera, Rodríguez Ramírez et al., "Geomorphological record», 113-115. La mención a la doble desembocadura por parte de autores posteriores (Pausanias o Avieno) se explicaría por las fuentes en las que se basaron.

92. En 1499 escribía Nebrija en su Muestra de la Historia de las Antigüedades de España que entonces el Guadalquivir tenía un solo brazo "por donde sale a la mar en / el puerto de san lúcar de barrameda", aunque las señales del otro brazo, que se cegó con los sedimentos acarreados por el río, "parece a- / gora cerca de lebrixa i las torres de asta hasta la costa por donde salía cerca de rota» (Nebrija, Muestra, cap. iiiif).

93. Sobre este hallazgo, Carriazo y Arroquía, «El tesoro».

94. Remitimos a la revisión de los parámetros temporales en Martín Ruiz, «El tesoro», especialmente páginas 103-107.

95. Menanteau, «Les anciens étiers», 40.

96. Mela 3.4; Plin. NH 3.10.

97. Sobre este santuario, Corzo Sánchez, "El santuario»; López Amador y Ruiz Gil, "Las ofrendas». Tradicionalmente se había identificado con Sanlúcar de Barrameda (Tovar, Iberische Landeskunde, 52-53.

98. Martínez Maganto ha demostrado que templos y santuarios localizados en puntos estratégicos y dedicados a divinidades vinculadas con la navegación sirvieron también como faros (Martínez Maganto, «Faros», 69). 


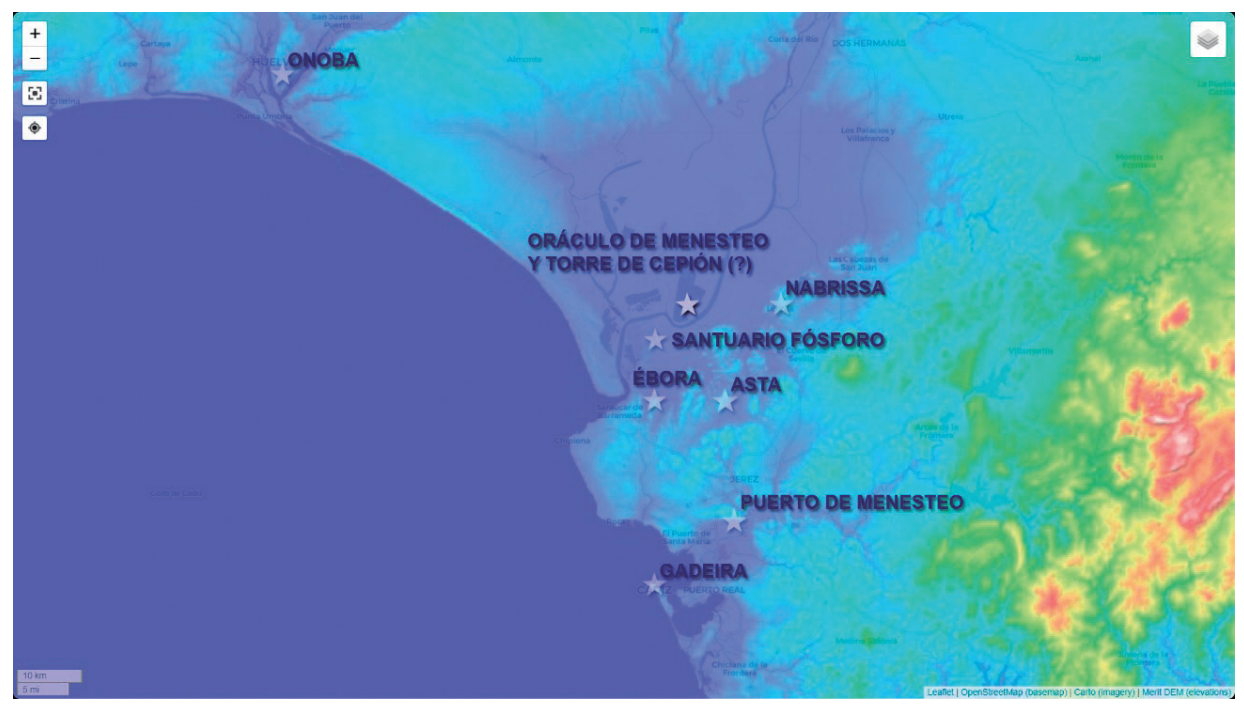

Fig. 2. Mapa con la ubicación de los puntos de referencia.

Elaborado a partir de https://es-es.topographic-map.com/maps/6olb/España/

diosa, $\varphi \omega \dot{\sigma} \sigma$ ороц ("portadora de la luz»), que es uno de los nombres cultuales de Ártemis-Hécate, en tanto que diosa lunar ${ }^{99}$. Estrabón también llama a esta divinidad Lux Dubia, "crepúsculo", que se refiere al «lucero del atardecer», identificado con Afrodita y, por lo tanto, también con la diosa fenicia Astarté. En este caso también estamos ante una divinidad muy útil para los marineros, ya que durante el crepúsculo (matutino/vespertino) se pueden ver las estrellas náuticas más brillantes, que eran las de primera y segunda magnitud, además de las principales constelaciones ${ }^{100}$.

Bien sea la diosa del santuario Ártemis-Hécate o Afrodita (Astarté fenicia), tras la que puede esconderse una divinidad prerromana de tipo astral, es evidente que el lugar estaba vinculado a la navegación, en uno de los puntos más peligrosos de este derrotero: la salida al océano. En este lugar los navegantes tendrían que maniobrar una nave zarandeada por la corriente fluvial del Guadalquivir y el oleaje del mar, que tras dejar la relativa calma de la navegación de interior se iba a enfrentar a los temporales atlánticos de la travesía hacia occidente o al paso del Estrecho si se dirigía a oriente. Qué mejor lugar para un santuario en el que los

99. Eur. IA 21; Hel. 569.

100. La gran ayuda que esto suponía para los navegantes queda testimoniada en los hallazgos marinos aparecidos en el santuario (López Amador y Ruiz Gil, "Las ofrendas», 280). 
marineros agradecían el haber llegado hasta allí o bien pedían a los dioses una travesía segura hasta su siguiente destino, un santuario que, por otra parte, pudo funcionar también como faro.

\begin{tabular}{|c|c|c|c|c|c|c|}
\hline & \multicolumn{2}{|c|}{ PARTEMIDORO } & \multicolumn{2}{|l|}{ ESTRABÓN } & \multicolumn{2}{|c|}{ MARCIANO } \\
\hline & Estadios & Км & Estadios & Км & Estadios & KM \\
\hline $\begin{array}{l}\text { Gadeira - Puerto } \\
\text { de Menesteo }\end{array}$ & 86 & $\begin{array}{l}12,9- \\
25,6 \\
\end{array}$ & & & $\begin{array}{l}\text { máx. } 80 \\
\text { mín. } 45\end{array}$ & $\begin{array}{c}12-23,8 \\
6,7-13,41 \\
\end{array}$ \\
\hline $\begin{array}{l}\text { Puerto de Me- } \\
\text { nesteo - Asta }\end{array}$ & 120 & $18-35,7$ & & & & \\
\hline $\begin{array}{l}\text { Puerto de la isla } \\
\text { - Asta }\end{array}$ & & & 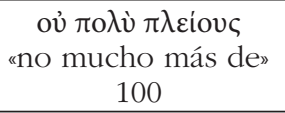 & $\begin{array}{c}\text { ca. } \\
18,5\end{array}$ & & \\
\hline $\begin{array}{l}\text { Asta - Baetis } \\
\text { (desembocadu- } \\
\text { ras) } \\
\end{array}$ & & & 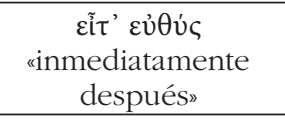 & & & \\
\hline $\begin{array}{l}\text { Baetis (desembo- } \\
\text { caduras) -Orácu- } \\
\text { lo de Menesteo y } \\
\text { Torre de Cepión }\end{array}$ & & & 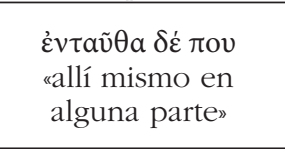 & & & \\
\hline $\begin{array}{l}\text { Oráculo de Me- } \\
\text { nesteo y Torre de } \\
\text { Cepión - Salida } \\
\text { al mar del Baetis, } \\
\text { Ébora, Santuario } \\
\text { de la diosa Fós- } \\
\text { foro }\end{array}$ & & & $\begin{array}{c}\dot{\varepsilon} v \tau \varepsilon \tilde{v} \theta \varepsilon v \\
\text { "desde aquí" }\end{array}$ & & & \\
\hline $\begin{array}{l}\text { Asta - Baetis } \\
\text { (desembocadura) }\end{array}$ & 84 & $12,6-25$ & & & $\begin{array}{l}\text { máx. 385 } \\
\text { mín. 285 }\end{array}$ & $\begin{array}{c}57,75-114,73 \\
42,7-84,9 \\
\end{array}$ \\
\hline
\end{tabular}

Fig. 3. Tabla con las distancias y expresiones periplográficas del derrotero mencionadas en el texto.

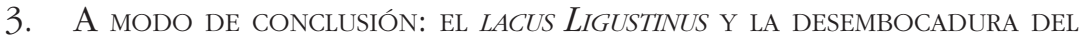
GuAdalquivir EN TIEMPOS DE EstrabóN

Gracias a los estudios realizados por el equipo del Proyecto Geoarqueológico de las Marismas del Guadalquivir conocemos mucho mejor la evolución de este mar interior, en continua transformación debido al influjo mareal y a la dinámica fluvial ${ }^{101}$. El punto de partida es una

101. De sus publicaciones destacamos principalmente Arteaga Matute y Roos, «El proyecto»; "Geoarchäologische Forschungen»; Schulz et al., «La línea costera». A las que se debe 
ensenada litoral cuya línea costera estaba en las inmediaciones de Sevilla y la desembocadura del Guadalquivir en la cabecera de la misma ( $c a$. 6000 a. C.). En torno a 2000 a. C. las orillas de este mar interior apenas se habían modificado, pero se había formado un delta en la zona de la desembocadura, que iba avanzando hacia el mar, al mismo tiempo que el proceso de sedimentación iba reduciendo la profundidad en el centro del lago. Durante el Bronce Final y periodo Orientalizante, el delta y la desembocadura del Guadalquivir se habrían desplazado a la altura de Coria del Río. Entre el siglo V a. C. y la conquista romana continuó el proceso de sedimentación tanto en las orillas como en el centro del lago, de manera que el delta siguió avanzando. Este proceso de sedimentación de origen continental acabó convirtiendo este mar interior en una llanura aluvial atravesada por un río poco definido, dividido en una red de pequeños canales divagantes, separados por islas sedimentarias, muchas de ellas pequeñas y temporales. Ya cerca del cambio de Era este modelo fluvial se transformó en un río meandriforme, con uno o varios canales principales en su mayor parte navegables, cuya desembocadura se fue desplazando hacia el sur, hasta las inmediaciones del estero de Lebrija. En este paisaje, además, se formaron cordones sedimentarios a lo largo de la costa que, no más tarde del siglo II d. C., aislaron la laguna del mar. Estos cordones o flechas litorales son el de Doñana, que creció $5 \mathrm{~km}$ hacia el sudeste, y de La Algaida, que mediante un tómbolo se unió al continente al norte de Sanlúcar de Barrameda ${ }^{102}$. El progresivo proceso de sedimentación, acelerado por la formación de estas flechas litorales, transformó los esteros en marismas, pero no fue antes de la Tardía Antigüedad o Alta Edad Media ${ }^{103}$.

En la realidad paisajística que se empieza a formar entre al siglo $\mathrm{V}$ a. C. y la conquista romana cobra sentido el derrotero de Estrabón, aunque quedan algunos cabos sueltos que posteriores estudios geoarqueológicos podrían aclarar. En este caso nos referimos a nuestra propuesta de una vía navegable directa que conectaría el puerto de Menesteo, ubicado en algún punto de la costa occidental del estuario del Guadalete, y la vida portuaria de la bahía de Cádiz con los esteros de Asta y Nabrissa y, en consecuencia, con "las desembocaduras del Guadalquivir». De esta manera, como ya hemos señalado, se evitaban los vientos y corrientes desfavorables de

añadir Rodríguez Ramírez et al., "Geomorfología», «Evolución costera» y "Geomorphological record»; Ferrer Albelda, García Vargas y García Fernández, «Inter Aestuaria»; Ménanteau y Vanney, "Geohistoria»; Borja Barrera et al., "Evolución".

102. Rodríguez Ramírez et al., "Geomorphological record", 115.

103. Arteaga Matute et al., «El problema», 123; Rodríguez Ramírez et al., "Geomorphological record», 115-116. 
circunnavegar la costa, así como los bajíos y barras presentes en el tramo entre las actuales Rota y Sanlúcar. Por otra parte, las distancias indicadas en el PArtemidoro y por Estrabón son concluyentes para rechazar la circunnavegación costera. De estar en lo cierto, se accedería directamente a las dos desembocaduras del Guadalquivir, desplazada ahora a la altura de la actual Nebrija, donde debemos situar la isla a la que se refiere Estrabón, una estructura deltaica de cierta entidad en la que podríamos situar el oráculo de Menesteo y la torre de Cepión. El lugar era, por lo tanto, un paso obligado para la navegación hacia el interior y hacia el océano o el Mediterráneo, y esto le convertía en un punto muy estratégico para ubicar un oráculo que se consultaría antes de iniciar el viaje; y también un monumento honorífico, visible para todo el que bajaba o subía por el Guadalquivir y que debido a su ubicación funcionaría como faro.

En el contexto paisajístico en el que tenemos, por un lado, una red de pequeños canales divagantes y una progresiva progradación costera, la salida al mar del Guadalquivir, que no su desembocadura, es en Estrabón un único canal, aunque hubo dos, uno principal, entre la flecha litoral de Doñana y la isla de La Algaida, y otro secundario, entre esta isla y las colinas de Sanlúcar de Barrameda. En este entorno nuevamente estamos ante un excelente punto para ubicar un santuario, en el lado occidental de este canal.

Es evidente, por lo tanto, que los resultados de los estudios geoarqueológicos en torno al lacus Ligustinus están refrendados por el geógrafo de Amasia, si bien sería conveniente avanzar en la línea de detectar esa posible vía directa de navegación entre la bahía de Cádiz y los esteros de Asta y Nabrissa.

\section{Bibliografía}

Alonso-Núñez, José Miguel. «Les informations de Posidonius sur la Péninsule Ibérique». L'Antiquité Classique 48 (1979): 639-646.

Alonso-Núñez, José Miguel. "Les renseignements sur la Péninsule Ibérique d'Artémidore d'Éphèse». L'Antiquité Classique 49 (1980): 255-259.

Antonelli, Luca. I Greci Oltre Gibilterra. Rappresentazioni mitiche dell'estremo occidente e navigazioni commerciali nello spazio atlantico fra VIII e IV secolo a. C. Roma: L'Erma di Bretschneider, 1997.

Arnaud, Pascal. Les routes de la navigation antique. Itinéraires en Méditerranée. Paris: Errance, 2005.

Arteaga Matute, Oswaldo y Anna-Maria Roos. «El proyecto geoarqueológico de las Marismas del Guadalquivir. Perspectivas arqueológicas de 
la campaña de 1992». Anuario Arqueológico de Andalucía 2 (1995a): 329-339.

Arteaga Matute, Oswaldo y Anna-Maria Roos. "Geoarchäologische Forschungen im Umkreis der Marismas am Río Guadalquivir (Niederandalusien)». Madrider Mitteilungen 36 (1995b): 199-218.

Arteaga Matute, Oswaldo et al. «El problema del lacus Ligustinus. Investigaciones geoarqueológicas en torno a las marismas del Bajo Guadalquivir». En Tartessos, 25 años después, 1968-1993. Congreso Conmemorativo del $V$ Symposium Internacional de Prehistoria Peninsular, 99-135. Jerez de la Frontera: Ayuntamiento de Jerez de la Frontera, 1995.

Blázquez Martínez, José María. Diccionario de las religiones prerromanas de Hispania. Madrid: Istmo, 1975.

Borja Barrera, Francisco et al. "Evolución de la llanura aluvial del bajo Guadalquivir durante el Holoceno medio-superior. Geoarqueología y reconstrucción paleogeográfica de la vega de Itálica (Sevilla, España)». Boletín Geológico y Minero 129.1-2 (2018): 371-420.

Bossina, Luciano. "Il cosiddetto "Papiro di Artemidoro». Dalla parte degli scettici». Antigüedad y Cristianismo 29 (2012): 285-320.

Canfora, Luciano. Il papiro di Artemidoro. Bari: Laterza, 2008.

Caro Bellido, Antonio. "Nabrissa (Lebrija, Sevilla). Los orígenes del núcleo urbano». Anales de la Universidad de Cádiz 3-4 (1986-1987): 55-70.

Caro Bellido, Antonio. Lebrija y el bajo Guadalquivir. Paleografía y fuentes clásicas grecolatinas. Lebrija: Agrija, 1998.

Carriazo y Arroquía, Juan de Mata. El tesoro y las primeras excavaciones de Ebora (Sanlúcar de Barrameda). Excavaciones Arqueológicas en España n. ${ }^{\circ}$ 69. Madrid: Ministerio de Educación y Ciencia, 1970.

Celestino Pérez, Sebastián y Carolina López-Ruiz. Tartessos and the Phoenicians in Iberia. Oxford: Oxford University Press, 2016.

Clarke, Katherine. «Strabo's Mediterranean». En The Routledge Companion to Strabo, editado por Daniela Dueck, 47-59. London - New York: Routledge, 2017.

Condello, Federico. "Artemidoro 2006-2011: l'ultima vita, in breve». Quaderni di Storia 74 (2011): 161-256.

Corzo Sánchez, José Ramón. "El santuario de La Algaida». En Cádiz y su provincia. Arte Antiguo, 137-171. Sevilla: Gener, 1984.

Cruz Andreotti, Gonzalo. "La visión de Gades en Estrabón. Elaboración de un paradigma geográfico». Dialogues d'Historie Ancienne 20.1 (1994): 57-85.

Domínguez Monedero, Adolfo. "Los oráculos, guía de la navegación y de la colonización». En La religión del mar. Dioses y ritos de navegación 
en el Mediterráneo Antiguo, coordinado por Eduardo Ferrer Albelda, M. ${ }^{a}$ Cruz Marín Ceballos y Álvaro Pereira Delgado, 67-90. Sevilla: Universidad de Sevilla, 2012.

Fabre, Paul. Les grecs et la connaissance de l'Orient. Lille: Université de Lille III, 1981.

Ferreiro López, Manuel Ángel. "Asta Regia según los geógrafos antiguos», Gades 9 (1982): 155-177.

Ferrer Albelda, Eduardo, Enrique García Vargas y Francisco J. García Fernández. "Inter Aestuaria Baetis. Espacios naturales y territorios ciudadanos prerromanos en el Bajo Guadalquivir», Mainake 30 (2008): 217-246.

Gallazzi, Claudio, Bärbel Kramer y Salvatore Settis. Il Papiro di Artemidoro (P. Artemid.). Milano: LED Edizioni Universitarie, 2008.

Geus, Klaus y Kurt Guckelsberger. «Measurement data in Strabo's Geography». En The Routledge Companion to Strabo, editado por Daniela Dueck, 165-177. London - New York: Routledge, 2017.

Gómez Espelosín, Francisco Javier, Antonio Pérez Largacha y Margarita Vallejo Girvés. La imagen de España en la Antigüedad clásica. Madrid: Gredos, 1995.

Gómez Muñoz, María Soledad. "Turris Caepionis, antiguo faro de Chipiona. Ubicación y visibilidad desde la costa en época romanan. En Construyendo la Antigüedad. III Congreso Internacional de Jóvenes Investigadores del Mundo Antiguo, coordinado por José Javier Martínez García et al., 353-380. Murcia: Universidad de Murcia, 2017.

González Fernández, Julián. "Colonia Hasta quae Regia dicitur». En Colonias de César y Augusto en la Andalucía romana, editado por Julián González Fernández y José Carlos Saquete Chamizo, 223-247. Roma: L'Erma di Bretschneider, 2011.

González Ponce, Francisco José. «El corpus periplográfico griego y sus integrantes más antiguos: épocas arcaicas y clásicas». En Los límites de la tierra: el espacio geográfico en las culturas mediterráneas, editado por Aurelio Pérez Jiménez y Gonzalo Cruz Andreotti, 41-75. Madrid: Ediciones Clásicas, 1998.

González Ponce, Francisco José. Periplógrafos griegos, I: Épocas arcaica y clásica, 1: Periplo de Hanón y autores de los siglos VI y $V$ a. C. Monografías de Filología Griega 19. Zaragoza: Prensas Universitarias de Zaragoza, 2008.

Güngerich, Rudolf. Die Küstenbeschreibung in der griechischen Literatur. Münster Aschendorff, $1975^{2}$. 
Hammerstaedt, Jürgen. "Artemidorus fr. 21 Stiehle and its relationship to the Artemidorus papyrus». Historia: Zeitschrift für Alte Geschichte 61 (2012): 309-324 y 357-361.

Kaplan, Philip. "The function of the early periploi». The Classical Bulletin 84.2 (2008): 27-46.

Lagóstena Barrios, Lázaro y Darío Bernal Casasola 2004: «Alfares y producciones cerámicas en la provincia de Cádiz. Balance y perspectivas». En Figlinae Baeticae. Talleres alfareros y producciones cerámicas en la Bética romana (ss. II a. C. - VII d. C.), editado por Darío Bernal Casasola y Lázaro Lagóstena Barrios, 39-124. Oxford: John and Erica Hedges Ltd., 2004.

López Amador, Juan José y José Antonio Ruiz Gil. «Las ofrendas del santuario púnico-gaditano de la Algaida (Sanlúcar de Barrameda)». En Cuaternario y Arqueología. Homenaje a Francisco Giles Pacheco, coordinado por Esperanza Mata Almonte, 271-281. Cádiz: Diputación Provincial de Cádiz y Asociación Profesional del Patrimonio HistóricoArqueológico de Cádiz, 2010.

Marcotte, Didier. "Le papyrus d'Artémidore: le livre, le texte, le débat». Revue d'Historie des textes 5 (2010): 333-371.

Martín Ruiz, Juan Antonio. «El tesoro de Ébora. ¿Conjunto Sacro de un santuario turdetano?». Takurunna 8-9 (2018-2019): 93-118.

Martín-Arroyo Sánchez, Daniel José. Colonización romana y territorio en Hispania. El caso de Hasta Regia. Barcelona: Universitat de Barcelona, 2018.

Martínez Maganto, Julio. "Faros y luces de señalización en la navegación antigua». Cuadernos de Prehistoria y Arqueología 17 (1990): 67-90.

Ménanteau, Loic. "Les anciens étiers de la rive gauche des marismes du Guadalquivir». Mélanges de la Casa de Velázquez 14 (1978): 35-72.

Ménanteau, Loic y Jean-René Vanney. «Geohistoria de la desembocadura del Guadalquivir». En El Río Guadalquivir. Del mar a la marisma, vol. II, coordinado por Javier Rubiales Torrejón, 17-28. Sanlúcar de Barrameda: Junta de Andalucía, 2011.

Montero Vítores, Jesús. «El yacimiento de Dehesa de Bolaños en el marco de la Bahía de Cádiz. De Portus Menesthei a Portus Gaditanus». Revista de Historia de Jerez 8 (2002): 35-66.

Moret, Pierre. "Artemidoro y la ordenación territorial de Hispania en época republicana". En Revisiones de Historia Antigua VII. Romanización, fronteras y etnias en la Roma antigua: el caso bispano, editado por Juan Santos Yanguas y Gonzalo Cruz Andreotti, 425-456. Gasteiz: Universidad del País Vasco, 2013. 
Nebrija, Antonio de. Muestra de las Antigüedades de España. Burgos: Fadrique Biel de Basilea, 1499.

Olaguer-Feliú y Alonso, Fernando. "Alejandro Magno y la arquitectura de ostentación». Anales de Historia del Arte 5 (1995): 10-18.

Olshausen, Eckart. «Der Periplus zwischen Seehandbuch und Literatur». En Weltwissen vor Kolumbus. Periplus, editado por Justus Cobet, 35-57, Berlin - Münster: Lit. Verlag, 2013.

Pajón Leyra, Irene. «Vicisitudes de un geógrafo: El papiro de Artemidoro y la discusión acerca de su autenticidad». Antigüedad y Cristianismo 29 (2012): 271-284.

Peña Olivas, José Manuel de la. «Señalización marítima del Mediterráneo en la Antigüedad». Ingeniería Civil 150 (2008): 103-116.

Plácido Suárez, Domingo. "Conocimiento y explotación de los pueblos del Noroeste hispano en la tradición literaria grecolatina». Gerión 32 (2014): 157-179.

Prontera, Francesco. «Períploi: sulla tradizione della geografía náutica presso i greci». En L'uomo e il mare nella civiltá occidéntale: da Ulisse a Cristoforo Colombo, Atti del Covegno (Genova 1992), 25-44. Genova: Edizioni Culturali Internazionali, 1992.

Roddaz, Jean-Michel. "Aux marges de l'Oikoumène: la quête des confins à la fin de la République et aut debut de l'Empire». En Confines. El extremo del mundo durante la Antigüedad, editado por Fernando Prados, Iván García y Gwladys Bernard, 95-105. Alicante: Universidad de Alicante, 2012.

Rodríguez Ramírez, Antonio et al. "Geomorfología de las terrazas fluviales del tramo bajo del río Guadalquivir: Implicaciones evolutivas». Geogaceta 21 (1996a): 183-186.

Rodríguez Ramírez, Antonio et al. «Evolución costera de la desembocadura del Guadalquivir en los últimos 6.000 años (SW de España)». Geogaceta 20.5 (1996b): 1086-1088.

Rodríguez Ramírez, Antonio et al. "Geomorphological record of extreme wave events during Roman times in the Guadalquivir estuary (Gulf of Cadiz, SW Spain): An archaeological and paleogeographical approach». Geomorphology 261 (2016): 103-118.

Ruiz Acebedo, Juan y Juan Manuel Campos Carrasco. «El litoral onubense y algarveño en el Papiro de Artemidoro: una nueva interpretación». Habis 40 (2009): 89-107.

Ruiz Mata, Diego. "Gadir, su estructura plural. Un modo de ver su fundación fenicia en el espacio y en el tiempo". Revista Onoba 6 (2018): 249-288. 
Salinas de Frías, Manuel. «El Hierón Akroteríon y la geografía de religiosa del extremo Occidente según Estrabón». En I Congreso Peninsular de Historia Antigua (Santiago de Compostela 1986), editado por Gerardo Pereira Menaut, 135-147. Santiago de Compostela: Universidad de Santiago de Compostela, 1988.

Salinas de Frías, Manuel. "Los elementos griegos en el libro III de la Geografía de Estrabón». En Arqueólogos, historiadores y filólogos: homenaje a Fernando Gascó, editado por Amado Jesús de Miguel Zabala, Francisco Eduardo Álvarez Solano y Jesús San Bernardino Coronil, tomo I, 103-126. Sevilla: Kolaios, 1995.

Schulz, Horst D. et al. "La línea costera holocena en el curso bajo del río Guadalquivir entre Sevilla y su desembocadura en el Atlántico. Informe preliminar sobre los trabajos de campo realizados en octubre y noviembre de 1992". Anuario Arqueológico de Andalucía 1992-II (1992): 323-327.

Tomassetti, José María. "Contribución al estudio del urbanismo antiguo en el Bajo Guadalquivir: el caso de Lebrija (Sevilla)». SPAL 6 (1997): 243262.

Tovar, Antonio. Iberische Landeskunde. Die Völker und die Städte des antiken Hispanien. Baden-Baden: Valentin Körner, 1974. 